\title{
INTERNAÇÕES POR ACIDENTES DE TRÂNSITO NO ESTADO DO AMAPÁ ENTRE OS ANOS 2014-2018
}

\section{ARTIGO ORIGINAL}

ARAÚJO, André Felipe Brito ${ }^{1}$

AMANAJÁS, Emarine Carla Almeida ${ }^{2}$

PAIXÃO, Eliana do Socorro de Brito ${ }^{3}$

DIAS, Claudio Alberto Gellis de Mattos 4

OLIVEIRA, Euzébio de ${ }^{5}$

DENDASCK, Carla Viana ${ }^{6}$

FECURY, Amanda Alves ${ }^{7}$

${ }^{1}$ Graduando em Medicina, Universidade Federal do Amapá (UNIFAP).

${ }^{2}$ Graduando em Medicina, Universidade Federal do Amapá (UNIFAP).

${ }^{3}$ Cientista Contábil. Doutora em Educação. Professora e pesquisadora do Curso de Secretariado Executivo do Campus Macapá, Universidade Federal do Amapá (UNIFAP).

${ }^{4}$ Biólogo, Doutor em Teoria e Pesquisa do Comportamento, Professor e pesquisador do Colegiado de Química, Campus Macapá, Instituto Federal do Amapá (IFAP).

${ }^{5}$ Biólogo, Doutor em Doenças Topicais, Professor e pesquisador do Curso de Educação Física da Universidade Federal do Pará (UFPA).

${ }^{6}$ Teóloga, Doutora em Psicanálise, pesquisadora do Centro de Pesquisa e Estudos Avançados- CEPA.

${ }^{7}$ Biomédica, Doutora em Doenças Topicais, Professora e pesquisadora do Curso de Medicina do Campus Macapá, Universidade Federal do Amapá (UNIFAP). 
ARAÚJO, André Felipe Brito. Et al. Internações por acidentes de trânsito no Estado do Amapá entre os anos 2014-2018. Revista Científica Multidisciplinar Núcleo do Conhecimento. Ano 04, Ed. 12, Vol. 01, pp. 18-25. Dezembro de 2019. ISSN: 24480959, Link de acesso: https://www.nucleodoconhecimento.com.br/saude/internacoespor-acidentes

\section{RESUMO}

Os acidentes de trânsito (AT) representam, atualmente, relevante questão de saúde pública, na medida em que podem provocar lesões físicas e/ou psíquicas irreversíveis. Esses tipos de acidentes são considerados eventos não intencionais, evitáveis, os quais, também, em caso de ocorrência, podem resultar em internações hospitalares e óbitos. Existem inúmeros fatores que contribuem com a casuística nos AT, dentre eles destacam-se vias públicas precárias, má sinalização e desrespeito pelas leis de trânsito. |Homens, adultos jovens e motociclistas são as principais vítimas deste sinistro. Este trabalho teve por objetivo analisar o índice de internações hospitalares por acidentes de trânsito no Estado do Amapá, no período de 2014 a 2018. A pesquisa teve abordagem quantitativa e a coleta de dados foi realizada no banco de dados do DATASUS SIH/SUS entre 2014 e 2018. Dentre os principais resultados, constatou-se que dos 15 municípios do Estado do Amapá, há total ausência de registros na plataforma, envolvendo os municípios de Cutias do Araguari, Ferreira Gomes, Itaubal e Vitória do Jari. É possível concluir que parece haver fragilidade no gerenciamento de informações acerca de internações suscitadas por acidentes de trânsito devido à incipiente inserção de registros na plataforma DATASUS. Adicionalmente, a ausência de informações no SIH/SUS do DATASUS, pode contribuir para a carência de recursos repassados para estes tipos de atendimentos.

Palavras-chave: Internações hospitalares, acidentes de trânsito, DATASUS.

\section{INTRODUÇÃO}

Segundo Mascarenhas e Barros (2015), as causas externas de morbidade e mortalidade abrangem os acidentes e as violências que provocam lesão física ou 
psíquica e que podem ou não levar ao óbito. Os acidentes (colisões no trânsito, afogamentos, intoxicações, etc) são eventos não intencionais e evitáveis, ocorridos no âmbito doméstico ou social (MASCARENHAS, BARROS, 2015).

A Organização das Nações Unidas (ONU) reconhece os acidentes de trânsito urbano como um sério problema de saúde pública em todo o mundo, em virtude de serem acompanhados por elevado índice de morbimortalidade (MENDONÇA et al., 2017).

Acidentes de trânsito (AT) representam um importante problema social e de saúde pública por serem importante causa de morte e lesões permanentes. No mundo, estima-se que 20 a 50 milhões de pessoas sejam vítimas de lesões não fatais decorrentes de AT, contribuindo para o aumento na prevalência de incapacidades (ANDRADE, JORGE, 2017; RAMOS et al., 2016). A lesão no trânsito é, atualmente, a principal causa de morte de crianças e adultos jovens, de 5 a 29 anos, sinalizando a necessidade de uma mudança na agenda atual de saúde, que negligenciou amplamente a segurança no trânsito (OMS, 2018).

No Brasil, de 2010 a 2015, os acidentes representaram aproximadamente $80 \%$ das internações realizadas no Sistema Único de Saúde (SUS) por causas externas. Os acidentes de transporte corresponderam a $22 \%$ delas. Refletem um impacto no setor de saúde devido à sobrecarga sobre os serviços de urgência e emergência, atenção especializada, assistência social e reabilitação. As repercussões negativas dos acidentes envolvem ainda custos sociais, econômicos e individuais (ANDRADE, JORGE, 2017; MINAYO, GUALHANO, 2016).

De acordo com o Ministério da Saúde, cerca de 70\% a $80 \%$ das vítimas de acidentes de trânsito são atendidas pelo SUS, sendo o segundo maior número de registros nos serviços públicos de urgência e emergência em todo o Brasil, resultando, entre 2010 e 2015, em mais de $R \$ 1,3$ bilhões gastos em atendimentos (BRASIL, 2017).

A taxa de mortalidade por acidente de transporte terrestre no país em 2009 foi de 19,6 óbitos por cem mil habitantes, sendo de 32,6 para homens e 7,1 para mulheres. As taxas mais elevadas ocorreram nas regiões Centro-Oeste e Sul com valores de 29,0 
e 25,4 por cem mil habitantes, respectivamente (NETO et al., 2012). Não foram encontrados dados satisfatórios da região Norte nos dados pesquisados.

\section{OBJETIVO}

Quantificar o número internações por acidentes de trânsito no estado do Amapá entre os anos 2014-2018.

\section{MÉTODO}

A pesquisa foi realizada no banco de dados DATASUS (http://datasus.saude.gov.br/). Foram coletados dados nacionais de acordo com as seguintes etapas: Foi selecionado o item "Acesso à Informação", depois "Informações de Saúde (TABNET)", "Epidemiológicas e Morbidade". Abriu-se uma nova página, e nela, foi selecionado "Morbidade Hospitalar do SUS (SIH/SUS)". Na página aberta selecionou-se o item "Causas Externas, por local de internação - a partir de 2008”. Na mesma página surgiu um mapa do território nacional no canto direito superior, e na caixa de seleção sob o mapa, clicou-se com o botão esquerdo e, na lista, foi selecionado "Amapá". Abriu-se uma nova janela. Na caixa "linha" selecionou-se "Município", na caixa "coluna" selecionou-se "Não Ativa", e na caixa "conteúdo" selecionou-se "Internações". Os dados coletados entre os anos de 2014 e 2018, selecionados, um a um, a partir da caixa "períodos disponíveis". Os demais dados foram coletados alterando a seleção da caixa "seleção disponível" para "caráter de atendimento" (dados retirados "todas as categorias" e "outros tipos de acidentes de trânsito"). Posteriormente selecionouse, na mesma caixa, "Faixa etária 1" e "Sexo". Os dados foram compilados no programa Excel, componente do pacote Office da Microsoft Corporation.

\section{RESULTADOS E DISCUSSÃO}

O quantitativo total de internações hospitalares por local de internação (município) foi de 175.774; por causa externa foi de 10.129; por acidente de trânsito foram 3; registrados no período analisado (2014-2018). A tabela 1 apresenta a distribuição detalhada considerando estas variáveis, além de população estimada, sexo e idade. 
Tabela 1 Internações Hospitalares no Estado do Amapá, no período de 2014 a 2018, considerando população estimada, local de internação, causa externa, internação por acidente de trânsito, sexo, idade e ano.

\begin{tabular}{|c|c|c|c|c|c|c|c|c|c|}
\hline Município & $\begin{array}{c}\text { População } \\
\text { estimada } \\
\text { (IBGE 2018) }\end{array}$ & $\begin{array}{c}\text { Internações } \\
\text { por local de } \\
\text { internação }\end{array}$ & $\%$ & $\begin{array}{c}\text { Internação } \\
\text { por causa } \\
\text { externa }\end{array}$ & $\%$ & $\left|\begin{array}{c}\text { Internações } \\
\text { por } \\
\text { acidentes de } \\
\text { trânsito }\end{array}\right|$ & \begin{tabular}{|l|} 
Sexo \\
Masc. \\
\end{tabular} & Idade & Ano \\
\hline Amapá & 9.029 & 1.308 & 0,74 & 43 & 0,42 & 0 & 0 & & \\
\hline Calçoene & 10.926 & 2.525 & 1,44 & 166 & 1,64 & 0 & 0 & & \\
\hline Cutias do Araguari & 5.864 & - & - & - & - & - & - & - & - \\
\hline Ferreira Gomes & 7.591 & - & - & - & - & - & - & - & - \\
\hline Itaubal & 5.387 & - & - & - & - & - & - & - & - \\
\hline Laranjal do Jari & 49.446 & 17528 & 9,97 & 2.076 & 20,50 & 0 & 0 & & \\
\hline Macapá & 493.634 & 121.662 & 69,22 & 7.124 & 70,33 & 1 & 1 & \begin{tabular}{|c|}
$25-$ \\
29 anos \\
\end{tabular} & 2015 \\
\hline Mazagão & 21.206 & 66 & 0,04 & 4 & 0,04 & 0 & 0 & & \\
\hline Oiapoque & 26.627 & 3.716 & 2,11 & 231 & 2,28 & 0 & 0 & & \\
\hline $\begin{array}{c}\text { Pedra Branca do } \\
\text { Amapari }\end{array}$ & 15.931 & 371 & 0,21 & 23 & 0,23 & 0 & 0 & & \\
\hline Porto Grande & 21.484 & 1.854 & 1,05 & 70 & 0,69 & 0 & 0 & & \\
\hline Santana & 119.610 & 26.667 & 15,17 & 389 & 3,84 & 1 & 1 & $\begin{array}{c}10- \\
24 \text { anos } \\
\end{array}$ & 2016 \\
\hline Serra do Navio & 5.306 & 43 & 0,02 & 3 & 0,03 & 1 & 1 & \begin{tabular}{|c|}
$20-$ \\
24 anos \\
\end{tabular} & 2018 \\
\hline Tartarugalzinho & 16.855 & 34 & 0,02 & 0 & 0,00 & & & & \\
\hline Vitória do Jari & 15.605 & - & - & - & - & - & - & - & - \\
\hline Total & 829.484 & 175.774 & 100,00 & 10.129 & 100,00 & 3 & 3 & & \\
\hline
\end{tabular}

Ministério da Saúde - Sistema de Informações Hospitalares do SUS (SIH/SUS) (BRASIL, 2017)

Observa-se que a base de dados não contém informações de internações de todos os municípios, a exemplo de Cutias do Araguari, Ferreira Gomes, Itaubal e Vitória do Jari. Cabe salientar que, excetuando o último, os demais estão localizados próximos a capital. Talvez seja pela disponibilidade e qualidade das informações sobre o endereço de residência, o que dificulta a correta identificação do endereço (MAIA, 2008).

A maioria das internações $(69,22 \%)$ ocorreram na capital Macapá, o que é compreensível em face desse município concentrar 59,51\% da população do Estado (BRASIL, 2018). Segundo Maia (2008), a capital além de concentrar a maior parte da população em termos percentuais, possui melhor e maior distribuição de 
equipamentos de infraestruturas como hospitais por exemplo. Tal fato, justifica a maior referência de pacientes para hospitais da capital Macapá.

Com relação às causas de internações, no que se refere às causas externas, 70,33\% estão concentradas em Macapá. Entretanto, chama atenção o índice atribuído ao município de Laranjal do Jari, que figura em $2^{\circ}$ lugar no ranking estadual com $20,50 \%$, embora a sua população seja a terceira maior do Estado. Para o município de Santana, segundo município mais populoso, com $14,42 \%$ dos habitantes, e que é conurbada com Macapá, há registro de apenas $3,84 \%$ dos casos. Diante disso, os valores dos indicadores de mortalidade e morbidade por AT podem ser maiores, pois não existe, no Brasil, um sistema de informações que integre bases de dados da Saúde e do Trânsito com o objetivo de definir os registros inespecíficos. Tal situação dificulta a estimação do número real de óbitos e feridos graves decorrentes de AT. (MANDACARU et al., 2018)

Quanto às internações por acidente de trânsito, na base de dados há registro de apenas três, um nos anos de 2015, um em 2016 e um em 2018, sendo todos do sexo masculino, com idade entre 10 a 29 anos. O fato de as únicas internações registradas serem de paciente do sexo masculino pode estar relacionada, segundo Costa e Mangueira (2014), a que os indivíduos desse sexo são os que mais se envolvem em acidentes, principalmente os motociclistas, por ser este um veículo de relativo baixo custo, fácil acesso e maior mobilidade urbana. De acordo com Mendonça, et al. (2017) a maioria dos óbitos e internações por esse agravo é observada no sexo masculino, na raça/cor da pele negra, nos adultos jovens (20-39 anos), em indivíduos com baixa escolaridade e entre motociclistas.

De acordo com Andrade et al (2009), ao começar a dirigir, os jovens pela inexperiência na condução de veículos, pela impulsividade, uso e até abuso de substâncias como álcool e drogas, passam a constituir população de alto risco para sofrer AT. Ainda segundo este mesmo autor, o sexo masculino é mais prevalente, visto que, este, por comportamento cultural e social, assumem maiores risco durante a condução de veículos, como abuso de velocidade e direção perigosa. 
Dados da Polícia Rodoviária Federal (PRF) apontaram que em 2018 ocorreram 1.052 AT nas estradas federais no Estado do Amapá, dos quais 689 vítimas são do sexo masculino. Esse número poderia ser maior, considerando que para 108 vítimas não houve o registro do sexo. Com relação a faixa etária houve maior prevalência de acidentes envolvendo pessoas com idade entre 15 e 45 anos, ou seja, adultos jovens (BRASIL, 2019).

Em relação às vítimas com ferimentos no Estado do Amapá, a PRF registrou 416 vítimas com ferimentos, e dentre esses, 127 foram acometidas por lesões graves não especificadas. Estes dados comprovam a necessidade de registros de internações decorrentes de AT, embora sejam de acidentes fora da área urbana, porém, com vítimas passíveis de internação. Ademais, houve 105 casos de vítimas sem confirmação de estado físico. Esta condição poderia implicar em um número maior de vítimas que necessitariam de internação (BRASIL, 2019).

Considerando os dados da PRF e que a frota de veículos automotores no Estado do Amapá é elevada (Figura 1) (BRASIL, 2019), sobretudo de automóveis $(41,18 \%)$ e de motocicletas $(33,16 \%)$, evidencia-se subnotificação dos casos de internações hospitalares registrados no DATASUS. Tais dados merecem ser registrados e analisados de forma adequada para talvez subsidiar formulação de políticas que visem à minoração, como também, meios de viabilizar internações e, consequentemente, tratamento adequado. 
Figura 1. Porcentagem de veículos no Estado do Amapá em 2018.

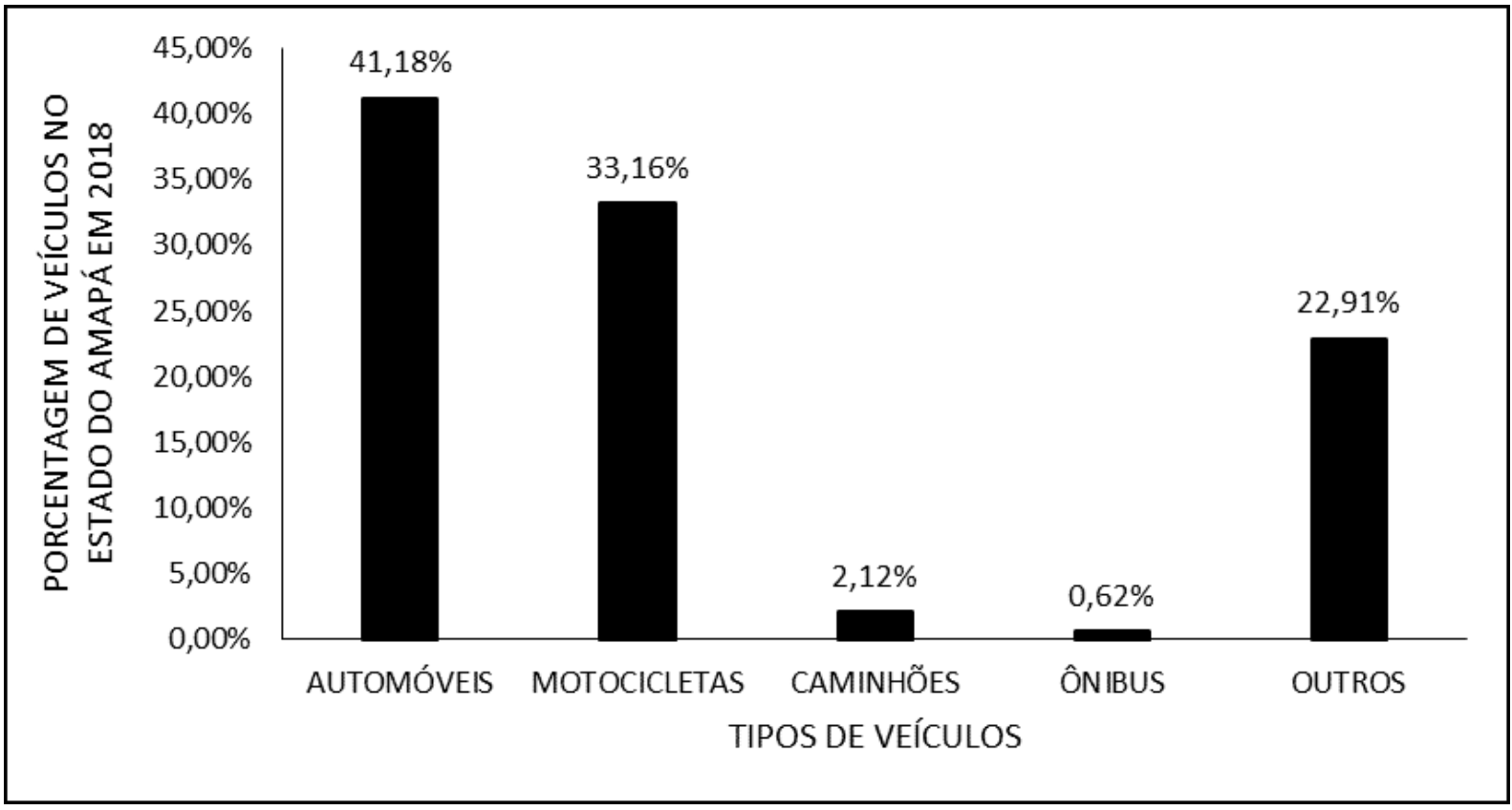

Nesse sentido, de acordo com Mendes et al. (2000), a abordagem dos sistemas de informação, como o SIH/SUS, bem como a sua correta alimentação, são bastantes promissores para subsidiar formulação e avaliação das políticas públicas de saúde, a exemplo da institucionalização da Lei Seca. Esta lei foi baseada em dados de acidentes com condutores alcoolizados. Não há necessidade de dados complexos, para projetar a minoração de acidentes, mas sim de boa qualidade. O dado deve denotar simplicidade e validade (MENDES et al., 2000), associado ao registro eficaz das notificações de morbidades, bem como suas causas nas plataformas como DATASUS-SIH/SUS.

\section{CONCLUSÃO}

A pesquisa revelou que a notificação estadual dos dados de morbidade de 2014-2018 relacionadas a AT parece ser falha e que a inexpressiva informação obtida no SIH/SUS dificulta a elaboração de programas ou avaliação de medidas já em vigor, relativas às políticas de educação de trânsito e, sobretudo, de saúde pública. Sem essas informações, não há como avaliar de forma objetiva o impacto de tais medidas na saúde coletiva da população amapaense. Diante desse quadro, é importante que 
os profissionais tomem para si o comprometimento com o preenchimento correto das informações que irão abastecer o DATASUS, por ser uma importante ferramenta de levantamento epidemiológico.

\section{REFERÊNCIAS}

ANDRADE, Silvânia Suely Caribé de.; JORGE, Maria Helena Prado de Mello. Internações hospitalares por lesões decorrentes de acidente de transporte terrestre no Brasil, 2013: permanência e gastos. Revista Epidemiologia e Serviços de Saúde, v. 26, n. 01, p. 31-38, 2017.

ANDRADE, Luciene Miranda de; LIMA, Maria Alzete de; SILVA, Carlos Helano Cosmo da; CAETANO, Joselany Áfio. Acidentes de motocicleta: características das vítimas e dos acidentes em hospital de Fortaleza-CE, Brasil. Revista Rede de Enfermagem do Nordeste, v.10, n.4, p.52-59. 2009.

BRASIL. IBGE. Cidades. Estimativa populacional 2018. Disponível em: $<$ https://cidades.ibge.gov.br/brasil/ap/cutias/panorama>. Acesso em: 30/07/2019.

BRASIL, Ministério da Saúde, 2017: Disponível em $<$ http://portalms.saude.gov.br/noticias/agencia- saude/29654-ministro-da-saudeapresenta-dados-e-acoes-para-seguranca-no-transito>. Acesso em: 10/02/2019.

BRASIL. PRF. Dados abertos. Disponível em: <https://www.prf.gov.br/portal/dadosabertos/acidentes\#acontent>. Acesso em: 30/06/2019.

COSTA, Maria Joerlane Calixto.; MANGUERIA, Jorgiana de Oliveira. Perfil epidemiológico de ocorrências no trânsito no brasil - Revisão Integrativa. SANARE, Sobral, V.13, n.2, p.110-116, jun./dez. - 2014.

MANDACARÚ, Polyana Maria Pimenta; RABELO, Ionara Vieira Moura; SILVA, Maria Aparecida Alves; TOBIAS, Gabriela Camargo; NETO, Otaliba Libânio de Morais. Óbitos e feridos graves por acidentes de trânsito em Goiânia, Brasil - 2013: magnitude e fatores associados. Revista Epidemiologia e Serviços de Saúde, v. 27, n. 2, 2018. 


\section{MAIA, PAULO BORLINA. Mortalidade por Acidentes de Trânsito no município de} São Paulo: uma analise intraurbana. Campinas, São Paulo. 2008

MASCARENHAS, Márcio Dênis Medeiros; BARROS, Marilisa Berti de Azevedo. Caracterização das internações hospitalares por causas externas no sistema público de saúde, Brasil, 2011. Revista Brasileira de Epidemiologia, v. 18, n. 4, p. 771-784, out-dez, 2015.

MENDES, Antônio da Cruz Gouveia; JUNIOR, Jarbas Barbosa da Silva; MEDEIROS, Kátia Rejane; LYRA, Tereza Maciel; FILHO, Djalma Agripino de Melo; SÁ, Domício Aurélio. Avaliação do sistema de informações hospitalares - SIH/SUS como fonte complementar na vigilância e monitoramento de doenças de notificação compulsória. Informe Epidemiológico SUS. v.9 n.2 Brasília jun. 2000. Disponível em: $<$ http://scielo.iec.gov.br/scielo.php?script=sci_arttext\&pid=S010416732000000200002>. Acesso em: 27/07/2019.

MENDONÇA, Marcela Franklin Salvador, SILVA, Amanda Priscila de Santana Cabral; CASTRO, Claudia Cristina Lima. Análise espacial dos acidentes de trânsito urbano atendidos pelo Serviço de Atendimento Móvel de Urgência: um recorte no espaço e no tempo. Revista Brasileira Epidemiologia, v. 20, n. 4, p. 727-741, out-dez, 2017.

MINAYO, Maria Cecília de Souza; GUALHANO, Luiza. Acidentes são a principal causa de morte violenta no mundo. Scielo em Perspectiva / Press Releases, 2016. Disponível em: <https:// pressreleases.scielo.org/blog/2017/01/05/acidentes-sao-aprincipal-causa-de-morte-violenta-no-mundo/>. Acesso em :11/02/2019.

NETO, Otaliba Libânio de Moraes; MONTENEGRO, Marli de Mesquita Silva; MONTEIRO, Rosane Aparecida; JUNIOR, João Bosco Siqueira; SILVA, Marta Maria Alves da; LIMA, Cheila Marina de; MIRANDA, Luiz Otávio Maciel; MALTA, Deborah Carvalho; JUNIOR, Jarbas Barbosa da Silva. Mortalidade por Acidentes de Transporte Terrestre no Brasil na última década: tendência e aglomerados de risco. Ciência \& Saúde Coletiva. v. 17. n. 9. p. 2223-2236. 2012. 
OMS. Organização Mundial da Saúde. Relatório sobre o estado global da segurança rodoviária, 2018. Genebra. Relatório de status global sobre segurança no trânsito. 2018. Geneva. 2018.

RAMOS, Tauan de Lima; AGUIAR, Airton Lima; ARRUDA, Eder Ferreira; PENICHE, Luciana Ribeiro da Silva; SOUSA, Cristiane Santos. PERFIL DA MORBIDADE HOSPITALAR POR ACIDENTES DE TRANSPORTE NO MUNICÍPIO DE RIO BRANCO-ACRE, BRASIL, NO PERÍODO DE 2014 E 2015. Enciclopédia Biosfera v. 13, n.24, p. 1466, 2016.

Enviado: Setembro, 2019.

Aprovado: Outubro, 2019. 